\title{
Pembentukan dan Makna Kata Majemuk dari Onomatope dan Bagian Tubuh Manusia dalam Bahasa Jepang di Media Sosial Twitter
}

\author{
Ni Nyoman Ayu Devi Pragasuri, Ngurah Indra Pradhana, I Made Budiana \\ PS. Sastra Jepang, FIB, Universitas Udayana, Bali, Indonesia \\ [devipragasuri.dp@gmail.com],[indra_pradana@unud.ac.id],[budi.hybrid@gmail.com]
}

\begin{abstract}
The title of this research is "Formation and Meaning of Compound Words from Onomatopoeia and Human Body Parts in Japanese on Social Media Twitter". This research focuses on the forming process and meaning of compound words from onomatopoeia and human body parts in Japanese on social media twitter. This research was analysed by using formal and informal method. Compound words formation analysis used word formation theory from Kageyama and Kishimoto (2016) and the meaning of compound words analysis used semantic theory from Chaer (2012) and characteristic of Japanese onomatopoeia from Akimoto (2002). The result of this research is on the 25 data was analyzed, there are 14 data formed from the composition process and 11 data formed from the composition process followed by the shortening process of the words and part of speech classification in all data has changed. For the meaning, 22 data have grammatical meaning and 3 data have lexical meaning and all data have derivative meaning from the basic onomatopoeia.
\end{abstract}

Keywords: compound words, onomatopoeia, composition, meaning, twitter

\begin{abstract}
ABSTRAK
Penelitian ini berjudul "Pembentukan dan Makna Kata Majemuk dari Onomatope dan Bagian Tubuh Manusia dalam Bahasa Jepang di Media Sosial Twitter". Penelitian ini berfokus pada proses pembentukan dan makna kata majemuk dari onomatope dan bagian tubuh manusia yang termuat dalam postingan di pengguna twitter di Jepang. Penelitian ini dianalisis menggunakan metode formal dan informal. Pembentukan kata majemuk dianalisis dengan teori pembentukan kata dari Kageyama dan Kishimoto (2016) dan makna kata majemuk dianalisis dengan teori semantik dari Chaer (2012) dan teori karakteristik Onomatope bahasa Jepang dari Akimoto (2002). Hasil yang diperoleh dalam penelitian ini adalah bahwa dari 25 data yang dianalisis terdapat 14 data terbentuk dari proses komposisi dan 11 data terbentuk dari proses komposisi yang dilanjutkan dengan proses pemendekan kata serta semua data mengalami perubahan kelas kata. Untuk maknanya, 22 data memiliki makna gramatikal dan 3 data memiliki makna leksikal serta semua data memiliki makna turunan dari kata onomatope dasarnya.
\end{abstract}

Kata Kunci : kata majemuk, onomatope, komposisi, makna, twitter

\section{Latar Belakang}

Negara Jepang merupakan salah satu negara yang sering menggunakan onomatope dalam kehidupan sehari-hari. Onomatope ini merupakan penggunaan kata-kata yang menarik dari bahasa Jepang karena dapat mengekspresikan berbagai arti dalam banyak situasi sehingga sangat perlu memahami onomatope agar dapat berbicara dan mengerti 
maksud yang disampaikan dalam bahasa Jepang dengan benar. Adapun pengertian dari kata onomatope adalah suatu kata yang subyektif dan berkenaan dengan panca indera karena mewakili makna yang diperoleh dari nada suara dasar (Tamori, 2010:iii). Onomatope bahasa Jepang dibagi menjadi beberapa macam istilah, diantaranya adalah giongo, gitaigo dan giseigo yang merupakan kelas kata khusus yang bentuk atau bunyinya serta maknanya terkait dengan ikonik (kemiripan antara bentuk dan makna) atau sesuai dengan simbol suara aslinya (Iwasaki, 2017:1).

Penggunaan onomatope dalam bahasa Jepang tidak hanya berdiri sendiri ataupun menjadi kata keterangan (adverbia) yang menjelaskan kata lainnya dalam suatu kalimat, namun ada juga penggunaan onomatope yang berkomposisi dengan kata lain dan membentuk suatu kata majemuk dalam bahasa Jepang. Kemenarikan bentuk kata majemuk dari penggabungan suatu kata dan onomatope inilah yang akhirnya menjadi dasar untuk melakukan suatu penelitian ini.

Agar penelitian tidak meluas maka penulis hanya meneliti kata majemuk yang terbentuk dari penggabungan kata onomatope dengan kata-kata yang berasal dari bagian tubuh manusia. Selain itu, manusia setiap hari menggerakan tubuh mereka untuk bergerak, bekerja, dan melakukan sesuatu sehingga kata majemuk yang terbentuk dari penggabungan kata onomatope dengan kata-kata yang berasal dari bagian tubuh manusia lebih banyak terbentuk dan lebih bervariasi. Penggunaan bentuk kata majemuk ini tidak hanya terdapat dalam percakapan sehari-hari, namun juga muncul dalam pesanpesan yang dimuat dalam media sosial. Oleh karena itu, media sosial dijadikan sumber data dalam penelitian ini, khususnya media sosial Twitter karena Twitter termasuk ke dalam 3 besar media sosial yang sering digunakan di dunia (Badri, 2011:132).. Penelitian ini hanya berfokus pada pembentukan dan makna kata majemuk dari onomatope dan kata lainnya dalam bahasa Jepang di media sosial Twitter. Penelitian yang sudah pernah dilakukan sebelumnya mengenai pembentukan dan makna kata majemuk dalam bahasa Jepang diantaranya Kwarini (2016), Wedayanti (2015), dan Primawan (2015), namun dengan sumber data dan pokok permasalahan yang berbeda.

\section{Pokok Permasalahan}

Berdasarkan latar belakang yang telah dipaparkan tersebut, maka yang dibahas dalam penelitian ini dapat dirumuskan sebagai berikut:

a) Bagaimanakah pembentukan kata majemuk dari onomatope dan bagian tubuh manusia dalam bahasa Jepang di media sosial Twitter? 
b) Bagaimanakah makna kata majemuk dari onomatope dan bagian tubuh manusia dalam bahasa Jepang di media sosial Twitter?

\section{Tujuan Penelitian}

Tujuan penelitian ini dibagi menjadi dua bagian, yaitu tujuan umum dan tujuan khusus.Secara umum penelitian yang dilakukan ini bertujuan untuk menambah wawasan serta pengetahuan para pembaca tentang kajian bidang ilmu linguistik, yaitu bidang morfologi dan semantik. Secara khusus penelitian ini bertujuan untuk mengetahui pembentukan dan makna kata majemuk dari onomatope dan bagian tubuh manusia dalam bahasa Jepang di media sosial Twitter.

\section{Metode Penelitian}

Data berupa kata majemuk dari onomatope dan bagian tubuh manusia diperoleh melalui media sosial Twitter dengan menggunakan metode simak dan teknik catat (Sudaryanto, 1993:133). Selanjutnya dianalisis dengan metode agih dan metode padan. Analisis pertama dilakukan untuk mengetahui proses pembentukan kata majemuk dari onomatope dan bagian tubuh manusia tersebut dengan menggunakan teori pembentukan kata oleh Kageyama dan Kishimoto (2016). Analisis kedua dilakukan untuk mengetahui makna yang terdapat dalam kata majemuk dari onomatope dan bagian tubuh manusia tersebut dengan menggunakan teori semantik dari Chaer (2012) yang didukung oleh teori karakteristik onomatope dari Akimoto (2002). Awalnya menganalisis makna leksikal dari setiap kata pembentuk dari kata majemuk tersebut. Kemudian, setelah makna leksikal selesai dianalisis maka selanjutnya menganalisis makna gramatikal dari kata majemuk yang telah mengalami proses gramatikal. Selanjutnya hasil analisis disajikan dengan metode formal dan informal (Zaim, 2014:114).

\section{Hasil dan Pembahasan}




\subsection{Pembentukan dan Makna Kata Majemuk dari Onomatope dengan Kepala}

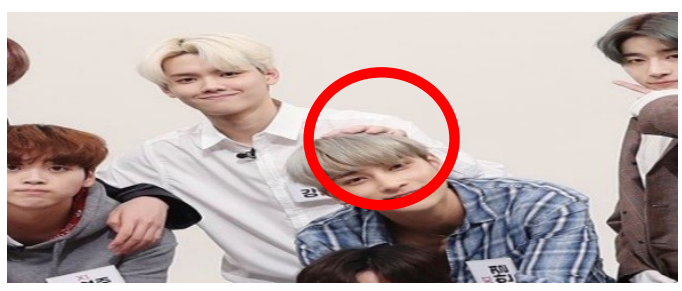

Gambar (1)

(1)@PiT_produce

$$
\begin{array}{lll}
\text { ミニ } & \text { に } & \multicolumn{1}{c}{\text { 頭ポン }} \\
\text { Mini } & n i \quad \text { atamapon } \\
\text { Mini } & \text { PAR } & \text { tepukan kep } \\
\text { の } & \text { かわいすぎ } \\
\text { no } & \text { kawaisugi } \\
\text { PAR } & \text { sangat lucu }
\end{array}
$$$$
\text { されてる }
$$
sareteru

Mini PAR tepukan kepala dilakukan

'Lucu sekali kepalanya ditepuk (atamapon) oleh Mini' [30/09/19 diakses dari Twitter]

$$
\begin{array}{cc}
\text { atama } \\
(\mathrm{N})
\end{array} \quad \begin{gathered}
\text { pon } \\
(\mathrm{Adv})
\end{gathered} \quad \begin{gathered}
\text { atamapon } \\
(\mathrm{N})
\end{gathered}
$$

Atamapon merupakan kata majemuk yang terbentuk akibat proses komposisi karena merupakan gabungan 2 buah kata dari atama yang merupakan kelas kata nomina dan pon yang merupakan kelas kata adverbia. Setelah mengalami proses komposisi, kedua kata tersebut bergabung menjadi atamapon dan kelas katanya berubah menjadi kelas kata nomina. Selain itu, atamapon juga bisa ditambahkan sufiks -suru melalui proses afiksasi sehingga kata majemuk atamapon ini merupakan kelas kata nomina khususnya verba nomina karena atamapon meskipun nomina tetap bisa diubah ke dalam bentuk kata kerja dengan penambahan sufiks -suru. Pada contoh postingan di atas, atamapon berafiksasi dengan verba bantuk pasif (ukemi), yaitu -sareru. Verba bantu -sareru sendiri berasal dari bentuk verba sufiks -suru.

Atama merupakan kata pembentuk atamapon yang artinya kepala dan dalam kata majemuk ini memiliki makna leksikal, yaitu bagian tubuh yang ada di atas wajah manusia. Sedangkan, pon merupakan bentuk onomatope berjenis gitaigo dengan bentuk penasalan suara karena berakhiran $-n$ untuk menunjukkan sesuatu kejadian dengan suara menggema dari benturan benda yang ringan. Pon memiliki 5 makna leksikal, yaitu 1) suara benda meledak atau jatuh dengan kuat; 2) suara ringan menepuk sesuatu; 3) keadaan benda yang dilempar, terbang dan kemudian memantul; 4) keadaan 
merespon dengan cepat; 5) keadaan ketika tidak bisa memikirkan apapun (Masahiro, 2007:464). Makna gramatikal atamapon adalah tindakan menepuk kepala dengan ringan. Kata onomatope pon dalam atamapon tidak menunjukkan suara menepuk seperti salah satu makna leksikalnya, melainkan tindakan menepuk sesuatu dengan ringan dan yang menjadi objeknya adalah kepala.

\subsubsection{Pembentukan dan Makna Kata Majemuk dari Onomatope dengan Rambut}

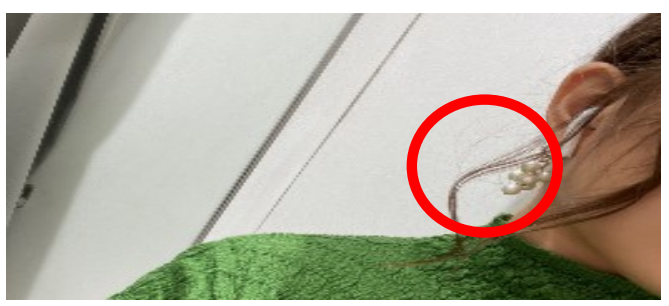

Gambar (2)

(2)@marynemui

$\begin{array}{lccc}\text { ユニクロユー } & \text { の } & \text { ニット } & \text { かわいい } \\ \text { Yunikuroyuu } & \text { no } & \text { nitto } & \text { kawaii } \\ \text { Uniqlo } U & \text { PAr pakaian rajutan lucu } & \text { lut } \\ \text { それにしても } & \text { 意外と } & \text { わたし } \\ \text { sorenishitemo } & \text { igai to } & \text { watashi } \\ \text { namun demikian } & \text { tak terduga } & \text { saya } \\ \text { 緑 } \quad \text { 似合う } & \text { なあ、、、、髢ボサ } \\ \text { midori niau } & \text { naa } & \text { kamibosa } \\ \text { hijau cocok } & \text { yaa } & \text { rambut kering }\end{array}$

'Pakaian rajutan Uniqlo U lucu. Namun demikian, di luar dugaan ternyata saya cocok dengan hijau yaa,,, rambut kering (kamibosa)' [02/10/19 diakses dari Twitter]

$$
\begin{aligned}
& \text { kami }+ \text { bosabosa } \rightarrow \text { kamibosabosa } \\
& \text { (N) (Adv) (proses komposisi) } \\
& \text { kamibosabosa } \rightarrow \text { kamibosa }
\end{aligned}
$$

Kamibosa merupakan kata majemuk yang terbentuk akibat proses komposisi karena merupakan gabungan 2 kata dari kami yang merupakan kelas kata nomina dan bosabosa yang merupakan kelas kata adverbia. Setelah mengalami komposisi, awalnya menjadi kamibosabosa lalu selanjutnya mengalami proses pemendekan kata khususnya backclipping karena yang mengalami pemendekan adalah morfem $\{b o s a\}$ yang ada di 
belakang kata sehingga menjadi kamibosa. Kelas kata dari kata majemuk kamibosa ini pun akhirnya menjadi nomina. Kata majemuk ini hanyalah nomina biasa bukan termasuk verba nomina karena tidak dapat berafiksasi dengan sufiks -suru. Hal ini dikarenakan faktor dari fungsi gramatikal dari onomatope bosabosa itu sendiri. Penggunaan onomatope bosabosa yang secara khusus berkaitan dengan rambut memiliki fungsi gramatikal sebagai nomina karena dalam penggunaannya diikuti oleh partikel no untuk menjelaskan kata benda setelahnya. Dalam kata majemuk ini karena berkaitan dengan rambut maka bosabosa pun memiliki fungsi gramatikal sebagai nomina. Setelah mengalami proses komposisi dengan kata kami yang juga merupakan kata nomina, maka kamibosa kelas katanya tetap nomina.

Kami merupakan kata pembentuk kami yang artinya rambut dan dalam kata majemuk ini memiliki makna leksikal, yaitu bulu yang tumbuh pada tubuh manusia terutama di kepala. Sedangkan, bosabosa merupakan bentuk onomatope berjenis gitaigo dengan bentuk pengulangan yang menunjukkan suatu keadaan yang berkelanjutan. Bosabosa ini memiliki 3 makna lesikal, yaitu 1) keadaan seperti orang dungu dan tidak melakukan apapun; 2) keadaan rambut yang kacau seperti tidak berminyak atau kering; 3) keadaan seperti kertas yang sangat lembut (Masahiro, 2007:441-442). Makna gramatikal kamibosa sama dengan makna leksikal dari onomatope bosabosa. Meskipun telah mengalami proses gramatikal, kata majemuk kamibosa tetap memiliki makna keadaan rambut yang kacau seperti tidak berminyak atau kering.

\subsubsection{Pembentukan dan Makna Kata Majemuk dari Onomatope dengan Dahi}

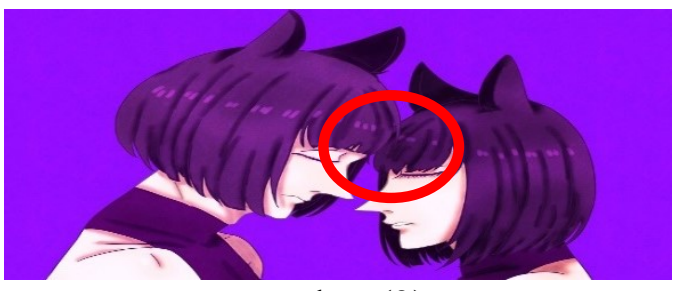

Gambar (3)

(3)@starm79958931 :

\begin{tabular}{|c|c|c|c|c|c|c|}
\hline 視愛 & な & 意味 & を & \multicolumn{2}{|l|}{ 込めて } & おでこコツン \\
\hline $\begin{array}{l}\text { Shinai } \\
\text { Sayang }\end{array}$ & $\begin{array}{l}n a \\
\text { adj }\end{array}$ & $\begin{array}{l}i m i \\
\operatorname{arti}\end{array}$ & $\begin{array}{l}\text { wo } \\
\text { PAR }\end{array}$ & $\begin{array}{l}\text { komete } \\
\text { memua }\end{array}$ & & $\begin{array}{l}\text { odekokotsun } \\
\text { benturan dahi }\end{array}$ \\
\hline$z$ & & 黒狜 & & 兄妹 & を & した \\
\hline & & & & & $\begin{array}{l}\text { wo } \\
\text { PAR }\end{array}$ & \\
\hline
\end{tabular}


'Saya telah menggambar kucing hitam bersaudara yang membenturkan dahi

(odekokotsun) dengan penuh kasih sayang'

[23/09/19 diakses dari Twitter]

odeko + kotsun $\rightarrow$ odekokotsun

(N) (Adv)

(proses komposisi)

Odekokotsun merupakan kata majemuk yang terbentuk akibat proses komposisi karena merupakan gabungan 2 buah kata dari odeko yang merupakan kelas kata nomina dan kotsun yang merupakan kelas kata adverbia. Setelah mengalami proses komposisi, kedua kata tersebut bergabung menjadi odekokotsun dan kelas katanya berubah menjadi kelas kata nomina. Selain itu, odekokotsun juga bisa ditambahkan morfem sufiks -suru melalui proses afiksasi sehingga kata majemuk odekokotsun ini merupakan kelas kata nomina khususnya verba nomina karena odekokotsun bisa diubah ke bentuk kata kerja dengan penambahan morfem sufiks -suru.

Odeko merupakan kata pembentuk odekokotsun yang artinya dahi atau kening dan dalam kata majemuk ini memiliki makna leksikal, yaitu bagian kepala sebelah depan atas yang sedikit menonjol antara rambut dan alis. Sedangkan, kotsun merupakan bentuk onomatope berjenis gitaigo dengan bentuk penasalan suara karena berakhiran $-n$ untuk menunjukkan sesuatu kejadian yang dengan suara menggema dari benturan benda yang ringan. Kotsun memiliki makna leksikal, yaitu suara benturan ringan ketika mengenai benda keras (Masahiro, 2007:131). Makna gramatikal odekokotsun adalah tindakan membenturkan antara dahi dan benda keras dengan ringan atau tidak keras. Pengertian odekokotsun dilihat dari gambar yang disisipkan di atas adalah membenturkan dahi dengan dahi. Dahi memiliki tekstur yang keras sehingga dapat menggunakan kata onomatope kotsun ini.

\subsubsection{Pembentukan dan Makna Kata Majemuk dari Onomatope dengan Dagu}

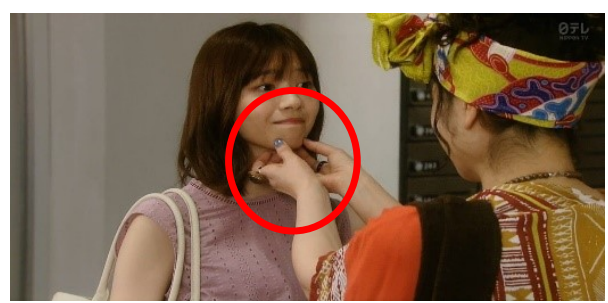

Gambar (4)

(4)@ugosho_honyo :

しっかり 顔見せて って 言った




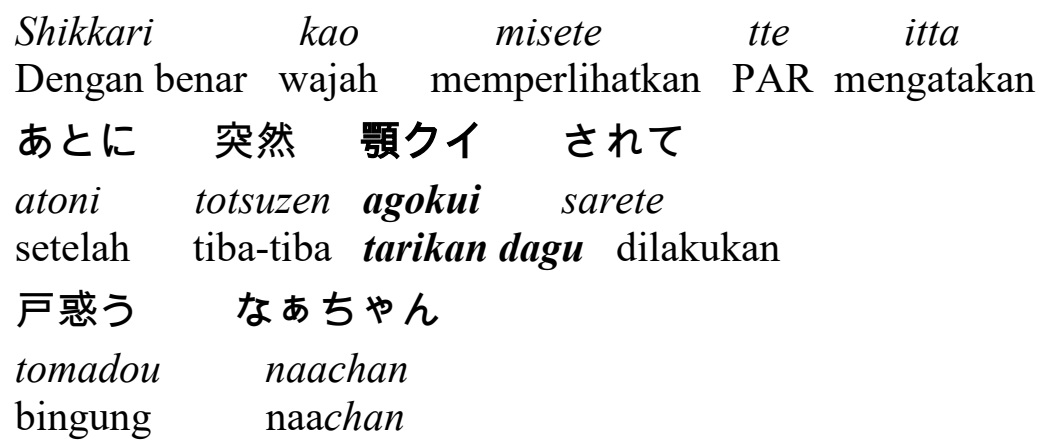

'Naachan yang kebingungan karena ditarik dagunya (agokui) secara tibatiba setelah disuruh memperlihatkan wajahnya dengan benar' [01/09/2019 diakses dari Twitter]

Agokui merupakan kata majemuk yang terbentuk akibat proses komposisi karena merupakan gabungan 2 buah kata dari ago yang merupakan kelas kata nomina dan kui yang merupakan kelas kata adverbia. Setelah mengalami proses komposisi, kedua kata tersebut bergabung menjadi agokui dan kelas katanya berubah menjadi kelas kata nomina. Selain itu, agokui juga bisa ditambahkan morfem sufiks -suru melalui proses afiksasi sehingga kata majemuk agokui ini merupakan kelas kata nomina khususnya verba nomina karena agokui bisa diubah ke bentuk kata kerja dengan penambahan morfem sufiks -suru. Pada contoh postingan di atas, agokui berafiksasi dengan verba bantuk pasif (ukemi), yaitu -sareru. Verba bantu -sareru sendiri berasal dari bentuk verba sufiks -suru.

Ago merupakan kata pembentuk agokui yang artinya dagu dan dalam kata majemuk ini memiliki makna leksikal, yaitu bagian di bawah mulut bagian bawah. Sedangkan, kui merupakan onomatope dari kata dasar yang tidak mengalami reduplikasi yang memiliki makna bahwa suatu hal terjadi sekali. Kui memiliki 2 makna leksikal, yaitu 1) keadaan menarik, mendorong, atau membelokkan sesuatu dengan ringan; 2) keadaan meminum minuman seperti osake dalam satu tegukan (Masahiro, 2007:82). Makna gramatikal agokui adalah tindakan menarik dagu. Kata onomatope kui dalam agokui tidak hanya menunjukkan keadaan menarik sesuatu seperti makna leksikalnya, melainkan juga menunjukkan tindakan menarik sesuatu dan yang menjadi objeknya adalah dagu. Pengertian agokui dilihat dari gambar yang disisipkan di atas adalah menarik dagu orang lain.

\subsubsection{Pembentukan dan Makna Kata Majemuk dari Onomatope dengan Lutut}

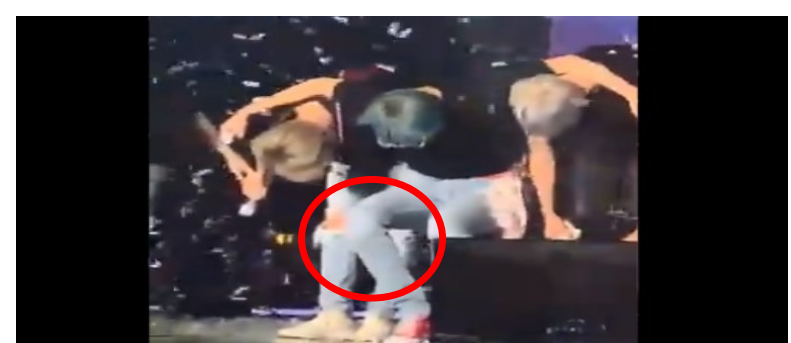




\section{Gambar (5)}

(5)@vope41

朝 から 泣きそう

Asa kara nakisou

Pagi dari menangis

膝ガク って そりゃそう だよね

hizagaku tte sorya sou dayone

lutut tertekuk PAR itu terlihat SHUU

あんなに も カッピング の 跡

annani mo kappingu no ato

sebegitunya juga likukan PAR tanda

も色 濃いし 疲れてる よね

mo iro koishi tsukareteru yone

juga warna pekat lelah SHUU

帰国したらゆっくり 休めます ように

kikokushitara yukkuri yasumemasu youni

setelah pulang perlahan bisa beristirahat semoga

'Dari pagi rasanya ingin menangis. Itu memang terlihat seperti lutut tertekuk (hizagaku) ya. Warna raut wajah pun gelap dan tanda menekuk pun sampai sebegitunya pasti sedang lelah ya. Setelah pulang ke negaramu, semoga bisa beristirahat dengan baik'

[4/03/2019 diakses dari Twitter]

Hizagaku merupakan kata majemuk yang terbentuk akibat proses komposisi karena merupakan gabungan kata dari hiza yang merupakan kelas kata nomina dan gakutt yang merupakan kelas kata adverbia. Setelah mengalami komposisi, awalnya menjadi hizagakutt lalu selanjutnya mengalami proses pemendekan kata khususnya backclipping karena yang mengalami pemendekan adalah morfem $\{t t\}$ yang ada di belakang kata sehingga menjadi hizagaku. Kelas kata dari kata majemuk hizagaku ini pun akhirnya menjadi nomina, khususnya verba nomina. Hal ini dikarenakan hizagaku bisa berafiksasi dengan sufiks -suru sehingga menjadi nomina yang dapat berubah menjadi verba.

Hiza merupakan kata pembentuk hizagaku yang artinya lutut dan dalam kata majemuk ini memiliki makna leksikal, yaitu bagian depan sendi yang menghubungkan paha dengan betis. Sedangkan, gakutt merupakan bentuk onomatope berjenis gitaigo dengan bentuk pemadatan suara untuk menunjukkan sesuatu yang terjadi secara tibatiba dan cepat. Gakutt ini memiliki makna lesikal, yaitu keadaan sesuatu yang dijaga agar lurus tiba-tiba membengkok (Masahiro, 2007:24). Sedangkan, makna gramatikal 
dari hizagaku adalah keadaan lutut yang lurus saat berdiri tiba-tiba membengkok. Pengertian hizagaku dilihat dari gambar yang disisipkan di atas adalah seseorang yang lututnya tiba-tiba membengkok karena kelelahan. Lutut manusia saat berdiri dijaga agar tetap lurus, namun saat kelelahan atau tersandung tidak jarang lutut tiba-tiba menjadi membengkok dan disinilah penggunaan kata onomatope gakutt digunakan sehingga berkomposisi dengan kata hiza menjadi kata majemuk hizagaku.

\section{Simpulan}

Berdasarkan analisis yang telah dilakukan, dapat ditarik beberapa kesimpulan mengenai pembentukan dan makna kata majemuk antara onomatope dan bagian tubuh manusia dalam bahasa Jepang di media sosial Twitter.

1) Dari 25 data yang dianalisis, kata majemuk yang terbentuk dari proses komposisi sebanyak 14 data dan kata majemuk yang terbentuk dari proses komposisi yang kemudian dilanjutkan dengan proses pemendekan kata sebanyak 11 data. Kata majemuk yang terbentuk dari kata onomatope berupa kata dasar dan berakhiran $\sim n$ selalu mengalami proses komposisi saja, sedangkan sisanya ada yang mengalami prosess pemendekan kata. Setelah mengalami proses pembentukan kata, kata majemuk yang memiliki kelas kata nomina biasa sebanyak 2 data, sedangkan kata majemuk yang memiliki kelas kata nomina namun bisa berafiksasi dengan sufiks -suru atau verba nomina sebanyak 22 data. Lalu, kata majemuk yang memiliki kelas kata adjektiva khususnya adjektiva $-n a$ sebanyak 1 data.

2) Setelah mengalami proses pembentukan kata, kata majemuk yang memiliki makna gramatikal sebanyak 22 data, sedangkan kata majemuk yang maknanya tidak berubah dan sama seperti makna leksikalnya sebanyak 3 data dengan karakteristik kata onomatope pembentuknya berupa kata dasar, pengulangan, pemadatan suara, penasalan suara, pemanjangan suara, dan penambahan morfem $\{r i\}$. Setiap kata majemuk yang terbentuk memiliki makna turunan dari kata onomatope dasarnya. Kata majemuk ini muncul untuk menjelaskan suatu tindakan maupun suatu keadaan dengan satu kata saja, tanpa perlu panjang lebar menjelaskan hal tersebut sehingga lebih efesien digunakan.

\section{Daftar Pustaka}


Akimoto, Miharu. 2002. Yoku Wakaru Goi. Tokyo: ALC.

Badri, Muhammad. 2011. Corporate and Marketing Communication. Jakarta: Universitas Mercu Buana

Chaer, Abdul. 2012. Linguistik Umum. Jakarta: Rineka Cipta

Ikuhiro, Tamori. 2010. Onomatope Gion Gitaigo wo Tanoshimu. Tokyo: Iwanami Shoten

Iwasaki, Noriko, dkk. 2017. The Grammar of Japanese Mimetics. New York : Routledge

Kageyama, T and Kishimoto, H. (2016). "Handbook of Japanese Lexicon and Word Formation". Berlin: Mouton De Gruyter

Kwarini, Ida Ayu Putri. 2016. "Pembentukan dan Makna Gairaigo dalam buku Ichinichi Sen En De Asoberu Minami No Shima Karya Hayashi Kazuyo" (skripsi). Denpasar: Universitas Udayana.

Masahiro, Ono. 2007. Nihongo Onomatope Jiten: Giongo Gitaigo 4500. Tokyo: Shogakkan.

Primawan, Randa Arkie. 2015. "Analisis Makna dan Asal Pembentukan Wakamono no Kotoba dalam Sosial Media Twitter" (skripsi). Jakarta: Universitas Bina Nusantara.

Surdayanto. 1993. Metode dan Aneka Teknik Analisis Bahasa. Yogyakarta: Duta Wacana Utama Press.

Wedayanti, N. P. L. (2015). PRODUKTIVITAS KATA HARASSMENT BERKOMPOSISI DALAM BAHASA JEPANG. PRASI, 10(19)

Zaim, M. (2014). Metode Penelitian Bahasa: Pendekatan Struktural. Padang: FBS UNP Press 